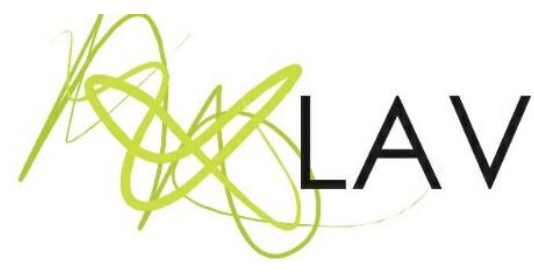

\title{
Infância e Educação Matemática: um conto sobre quando, enfim, somos verão
}

Childhood and Mathematics Education: a tale about when, finally, we are summer

Amanda Silva de Medeirosi Universidade Federal de Mato Grosso do Sul

Aparecida Santana de Souza Chiarii Universidade Federal de Mato Grosso do Sul

\section{Resumo}

Este relato de experiência apresenta um conto que mescla elementos reais e ficcionais, disparado a partir de produções de crianças de 6 e 7 anos, realizadas para uma pesquisa de mestrado, finalizada em 2018. No reencontro com essas produções, o texto se compõe enquanto proposta de subversão a modelos estabelecidos, em um movimento de criação de possibilidades. Assim, entrelaçam-se discussões entre infância e educação geradas pela arte que aqui é entendida numa perspectiva de realização, de fazimento de mundos. Apresenta-se, com isso, a abertura para sair de lugares já estabelecidos e habitar outros, desconhecidos, possibilitando que a infância não seja entendida com a falta, mas sim como convite, abertura, novidade, revolução, não só na educação, mas também em modos de viver.

Palavras-chave: produções imagéticas, formação, arte.

\begin{abstract}
This article presents a short story, which mixes real and fictional elements, generated from the productions of 6 and 7 year-old children, for a Master's degree research, completed in 2018. In the reunion with these productions, the text is composed as a proposal of subversion to established models, in a movement of creation of possibilities. Thus, discussions between childhood and education generated by art are intertwined, which is understood here from a perspective of realization, of making worlds. With this, there is an opening to leave previously established places and inhabit others, unknown, allowing childhood not to be understood with the lack, but as an invitation, openness, novelty, revolution, not only in education, but also in ways of living.
\end{abstract}

Keywords: imagery productions, formation, art.

Enviado em: 30/04/21 - Aprovado em: 09/06/21

\section{Introdução}

Pois arte é infância. Arte significa não saber que o mundo já é, e fazer um. Não destruir nada que se encontra, mas simplesmente não achar nada pronto. Nada mais que possibilidades. Nada mais que desejos. E, de repente, ser realização, ser verão, ter sol. Sem que se fale disso, involuntariamente. Nunca ter terminado. Nunca ter o sétimo dia. Nunca ver que tudo é bom (RILKE, 2007, p. 192). 
A escrita deste relato é verão. Surge a partir de um reencontro com produções de crianças e do que elas podem causar em nós. Produções realizadas durante a pesquisa de Mestrado das autoras deste relato de experiência. Produções de imagens, de desenhos, de escritas e de falas que agora, revisitadas, estremeceram-nos e nos encorajaram a escrever de um outro modo, para falar sobre nossas formações na educação e na vida. Nas próximas páginas, apresentamos um conto que mescla elementos reais e ficcionais, sobre infância e Educação Matemática, que surge da arte, aqui entendida na direção proposta por Rilke (2007), como abertura para o fazer de mundos, como o desaprender de achar coisas prontas. Arte que é infância e que inunda as produções das crianças, fazendo-nos ser realização.

Para isso, é preciso dizer que essa composição se faz com diversos autores, que se misturam. Essa escrita é fruto do abandono da língua fria, dando lugar a uma escrita guiada por marcas (Ribetto, 2016; Rolnik, 2016). Sendo assim, os autores que nos ajudaram nesse processo são citados em notas de rodapé (por ser um conto esta opção se deu também pela estética do texto) nos trechos em que são nossas principais referências. Processo difícil, visto que eles estão em cada linha deste texto, junto conosco, emaranhados e reverberando neste conto. Processo necessário, pois, por mais que escapemos em alguns momentos de nossa formação, ela ainda é nosso maior direcionamento. As imagens usadas na composição não possuem título, pois é impossível, para nós, nomeá-las. São produções das 21 crianças que nos ensinaram a desaprender. Apresentamos com isso uma escrita que se faz enquanto subversão a modelos prontos e esperados. Não como forma de excluir esse modo dado, mas como potência para criar possibilidades, para sermos (quem escreve e quem lê) verão.

\section{O vilarejo}

O vilarejo onde vivo é um dos muitos de nossa sociedade. Ele é rodeado de colinas e por aqui parece que o sol nunca está, de fato, aparecendo. Ele é dividido em três partes, para um melhor funcionamento. Uma delas é a parte central, onde funcionam bancos, lojas, mercados e todos os outros comércios e serviços essenciais. Ela é habitada por aqueles que, como eu, estão na idade da produção, de fornecer serviços para que o vilarejo continue a funcionar plenamente.

Há uma ponte que separa o centro do vilarejo de outra parte, bem menor, com apenas um prédio enorme, de cinco andares, onde os pais de nosso vilarejo deixam os estrangeiros para cumprir suas atividades. Os estrangeiros são aqueles que estão iniciando a vida, adentrando ao nosso mundo e precisam aprender nossos modelos de formação 
para nos ajudar a construir uma sociedade melhor ${ }^{1}$. Para isso, temos um prédio de formação em que cada andar abriga uma fase. O primeiro recebe os estrangeiros de idade até cinco anos para a formação não obrigatória. O segundo andar abriga os que iniciam a formação obrigatória, entre seis e dez anos. No terceiro andar, aqueles com idade entre 11 e 14 anos. O quarto andar abriga os estrangeiros que estão finalizando a formação obrigatória, com idade entre 15 e 17 anos. O último andar é habitado pelos adultos que trabalham ali. O prédio é organizado claramente para mostrar a hierarquia entre os sujeitos. Quanto mais alto, mais perto da formação necessária para atuar no vilarejo. A formação de nosso vilarejo continua para além da fornecida no prédio do outro lado da ponte, mas ela continua aqui, no lado da produtividade, pois já há formação suficiente para que se possa atuar de algum modo no centro².

Por fim, há a outra parte do vilarejo, para a qual me dirijo agora. É a parte onde ficam os aposentados, aqueles que já não contribuem mais para o funcionamento. É lá que fica a casa de minha avó. As paredes da casa, que outrora eram brancas, estão repletas de marcas de patas de animais, escritos de lápis de cor e beijos marcados por batom. Rastros de um outro tempo, quando os netos brincavam por ali. Dia desses soube que tentaram pintar, mas minha avó não permitiu. Disse que cor nenhuma seria melhor do que a pintura feita pelo tempo. É uma das poucas transgressões que ela ainda realiza estando em uma idade em que quase tudo é feito pelos outros.

Eu a vejo de longe. Está sentada na beira da mesa que fica na varanda, de frente para a cozinha. Está ouvindo o rádio que, fielmente, é ligado todos os dias às seis horas da manhã. É difícil chegar lá e encontrá-la de outro modo. Consigo sentir o cheiro de algo assando, o que também é comum. A casa de vó sempre tem algo que acabara de sair do forno.

Eu a chamo e ela imediatamente sorri. Mas demora a vir me cumprimentar. Tem uma notícia no rádio que parece muito importante. Depois de se informar e me contar das novidades, ela me leva à cozinha, para me mostrar o bolo de chocolate que fez para mim. Sirvo-me de um pedaço quente, como eu gosto, e conversamos sobre a vida. Enfim, voltamos para a varanda e ela me diz:

- Sua mãe me contou que você está na última fase do seu curso. Que amanhã você vai apresentar seus resultados.

Ela parece muito orgulhosa, mas surpresa também. Eu sempre fui muito estudiosa e é estranho que eu esteja sentada na varanda de minha avó, comendo bolo de chocolate,

\footnotetext{
1 KOHAN (2005)

2 KOHAN (2004)
} 
na véspera da apresentação dos resultados de minha pesquisa. Eu deveria estar estudando, mas não tenho conseguido. E é por isso que estou aqui.

- Sim vó, é amanhã. Passou rápido, não é? Estou bem nervosa.

- Mas você já estudou, já está tudo pronto?

- Sim, na verdade, tem duas coisas prontas e é justamente por isso que estou aqui. Vim contar para a senhora o que aconteceu e pedir um conselho.

Minha avó adora ouvir histórias. Com certeza, ela gosta mais de contar, mas ouvir é sua segunda paixão. Ela, de certa forma, tem relação com as coisas que vou contar, então no meio de minhas angústias, estar com ela me pareceu o certo.

Minha avó se levanta pesadamente e desliga o rádio. Agora sua atenção está em mim, me tornei mais interessante que as notícias policiais.

- Pode contar minha filha. Já tem mistura para a janta, e já fiz um pão para amanhã cedo. Posso te ouvir.

E então começo a contar.

Eu sempre fui excelente em minha formação. Ótimas notas, silenciosa, obediente. Certa vez, ouvi de uma formadora que eu era um exemplo, pois tinha terminado a lição e "não abria a boca nem para cuspir". Gostava do ambiente do prédio do outro lado da ponte e também gostava de formar. Foi natural querer me tornar formadora. No entanto, ao terminar esse primeiro curso quis ir além. Poderia formar os formadores. Pareceu-me uma boa opção. Segui adiante.

No curso que estou terminando há mais formação, também em sala de aula, onde ficamos enfileirados, com pessoas nos formando. Certo dia, perguntei-me quando é que isso termina, de ter gente formando outros para formarem também.

Na última parte do curso de formação, fazemos pesquisa. Vamos a campo, para os espaços formativos, desenvolver propostas para analisar e apontar pontos de fracasso e sucesso. Antes de ingressar nesse curso, passei alguns anos formando estrangeiros do terceiro andar, ensinando matemática, mas percebia certa aversão deles com a disciplina. Estava ali algum indício de fracasso que prejudicava essa formação. Agora, ao desenvolver minha pesquisa, decido seguir por esse caminho, vou a campo investigar a formação matemática dos estrangeiros do segundo andar.

Tenho alguém que me orienta na pesquisa - Isadora, minha orientadora. Em uma de nossas orientações, Isadora me propõe uma forma diferente, para que os alunos 
respondam minhas questões: por vídeo. No início, acabo tendo medo, mas confio em minha orientadora. Ela é diferente da maioria e isso é visível. Algo na forma de olhar, de dizer, da postura. Ela tem uma sensibilidade fora da curva que eu quero alcançar. Livrarme do medo do que escapa parece ser um bom começo para isso, então decidi seguir com a ideia. Conversamos e decidimos que os estrangeiros podem também escrever e desenhar para responder à questão.

Quando chega o dia de ir ao outro lado da ponte, sinto-me com as pernas bambas. Preparei-me, sei os roteiros, mas o nervosismo não vai embora. Minha orientadora está ao meu lado e tenta me acalmar enquanto eu reclamo:

- Eu nunca estive lá, não com estrangeiros tão novos. Quando os via eles já eram mais semelhantes a nós. E se eu não conseguir controlá-los?

- Tudo o que acontecer lá, é pesquisa. O que você vai fazer com o que os alunos vão produzir? É sobre isso a pesquisa. Se acalme e vá. Você também já foi estrangeira um dia.

Tento me acalmar ao atravessar a ponte, a fronteira.

Os estranhos estão lá, em toda a parte. É aqui que os estrangeiros aprendem nossa língua, nossos modos de viver, de agir ${ }^{3}$. Foi aqui que ouvi o elogio sobre não abrir a boca para cuspir. O lugar parece igual ao que eu me lembrava, com poucas mudanças. Encontro Valentina, a formadora dos estrangeiros com os quais eu vou pesquisar. Eles são uns dos mais novos, têm entre seis e sete anos, iniciando a formação. Ela me recebe e me leva até eles. Fala em um tom extremamente baixo e controlado, mas que traz consigo muita autoridade. Isso é visível, pois não há um único som na sala além de sua voz. Os estrangeiros estão enfileirados em sua sala, sentados em cadeiras altas demais, o que faz com que possam balançar suas pernas vez ou outra para lá e para cá. É o único movimento que vejo deles.

- Turma, essa é a Laura, uma formadora que fará algumas atividades com vocês. Ela ficará conosco alguns dias e peço a colaboração de todos. O comportamento de vocês vai valer nota, por isso é importante que vocês façam tudo o que ela pedir.

Acalmo-me quando a professora diz isso, pois significa que existe uma chance de que os estrangeiros colaborem. Já ouvi dizer que nessa idade eles são impetuosos e eu mesma me lembro das vivências quando estava aqui sendo formada. Enquanto Valentina passa outras orientações para os estrangeiros, tento contar quantos são: 21 no total. Um número grande.

${ }^{3}$ CHISTÉ; MIZUSAKI; ANDRADE (2015). 
- Tudo bem Laura, você pode começar quando quiser.

- Olá. Como a formadora disse eu vou desenvolver algumas atividades com vocês. Vou propor primeiro uma atividade com todos. Vocês gostam de desenhar?

Demorou quatro encontros para finalizar as atividades. Os alunos desenharam, escreveram e gravaram sempre com uma mesma pergunta direcionando as atividades: o que é matemática?

A gravação foi a parte mais difícil, pois eles saíram da sala, do controle, e ficaram livres. Volta e meia eu os perdi de vista. Em outros momentos eles passavam correndo e gargalhando, derrubando o celular que eu havia dado para a gravação.

Quando finalmente terminei, me dediquei a analisar as produções e elaborar o relatório final. Lancei a pergunta e tinha as respostas que eles teriam que dar. O que é matemática? Esperava que eles mostrassem números, operações, unidades de medida. O que não se encaixasse nisso seria problematizado para que essa lacuna fosse preenchida.

Debrucei-me sobre as produções e adentrei ao mundo dos estrangeiros.

- Espere um minuto - diz minha avó - Você perguntou para os estrangeiros já sabendo a resposta?

Paro de contar e olho para ela com certa vergonha. Confirmo.

- Sim vó, eu já sabia a resposta para aquelas perguntas. Justamente por isso, caso eles errassem, eu tentaria descobrir onde estamos fracassando em nossa formação. Iria propor coisas para que essas respostas possam ser padronizadas em próximas experiências.

- E foi isso que você fez?

- É por isso que estou aqui, vó. Eu não consegui.

A pergunta lançada aos estrangeiros foi: o que é matemática? Eu já sabia a resposta da pergunta. Não era uma descoberta, mas sim a busca pela afirmação de que os estrangeiros estavam no caminho certo, progredindo para o melhor de nosso vilarejo ${ }^{4}$. A escrita, as imagens, os desenhos seriam uma forma de que eles, com a linguagem ainda

${ }^{4}$ CHISTÉ (2015).

Revista Digital do LAV - Santa Maria - vol. 14, n. 2, p. 281 - 296 - mai./ago. 2021 ISSN 1983 - 7348 
em formação, pudessem dizer essas coisas de maneira mais completa. As respostas seriam indicativas para ajustarmos o caminho, fazer com que esses estrangeiros se formassem efetivamente para melhorar nossa sociedade.

Algumas dessas imagens fizeram sentido para mim, indicaram que estávamos no caminho certo.

Apenas uma estrangeira escreveu. Pareceu gostar de matemática, mas há um erro de escrita. Anoto isso, para nos debruçarmos depois. Precisa ser corrigido.

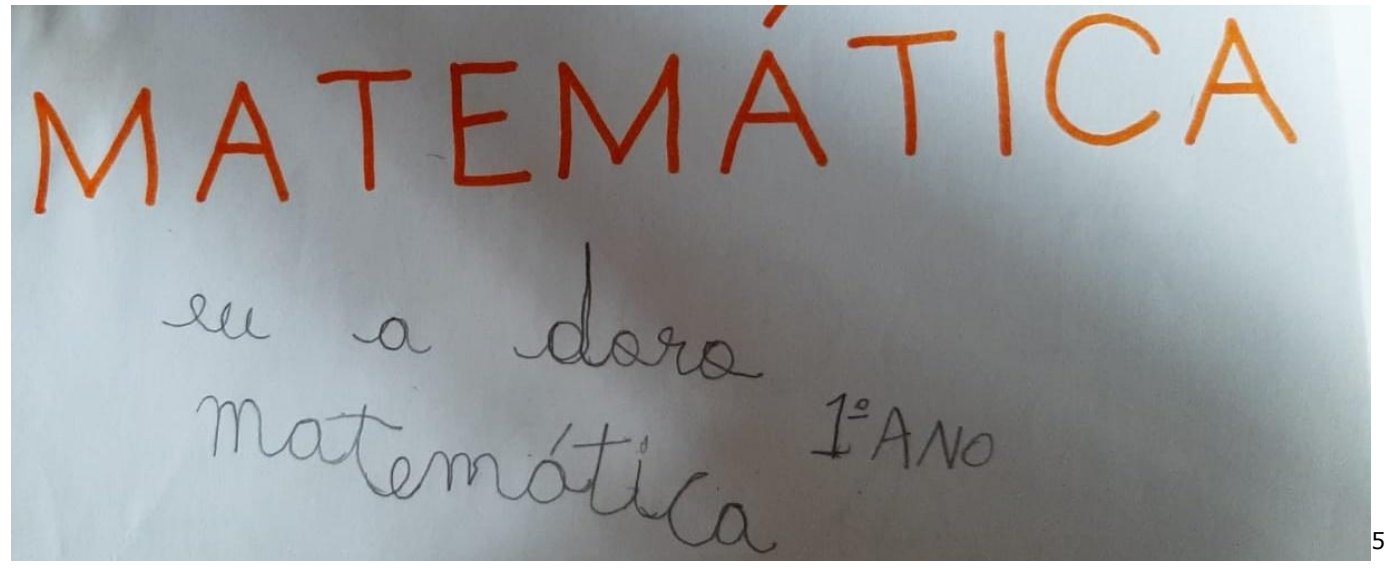

Há então desenhos. E com isso já começo a sentir um incômodo. Há número, mas há outras coisas rabiscadas ali, das mais diversas.
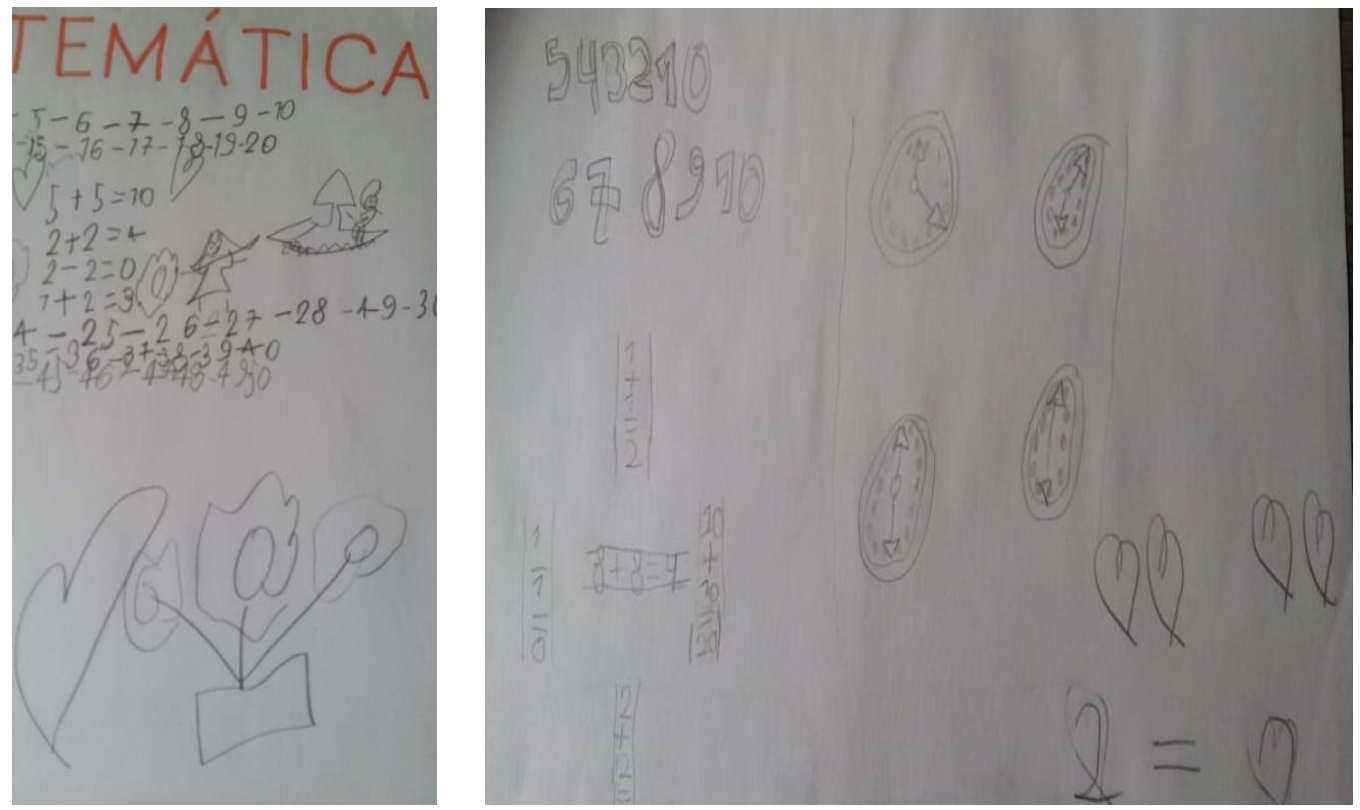

\footnotetext{
${ }^{5}$ As imagens apresentadas neste texto são oriundas da pesquisa de mestrado de Medeiros (2018), primeira autora deste texto, pesquisa esta que foi orientada pela segunda autora do artigo. As imagens foram produzidas por crianças de 6 e 7 anos, alunas do $1^{\circ}$ ano do Ensino Fundamental de uma escola particular do município de Miranda/MS. Em grupos de 3 ou 4, com um celular nas mãos, as crianças saíram pela escola gravando o que consideravam ser matemática. Declaramos ter autorização para o uso das imagens.
} 
E há também só outras coisas.

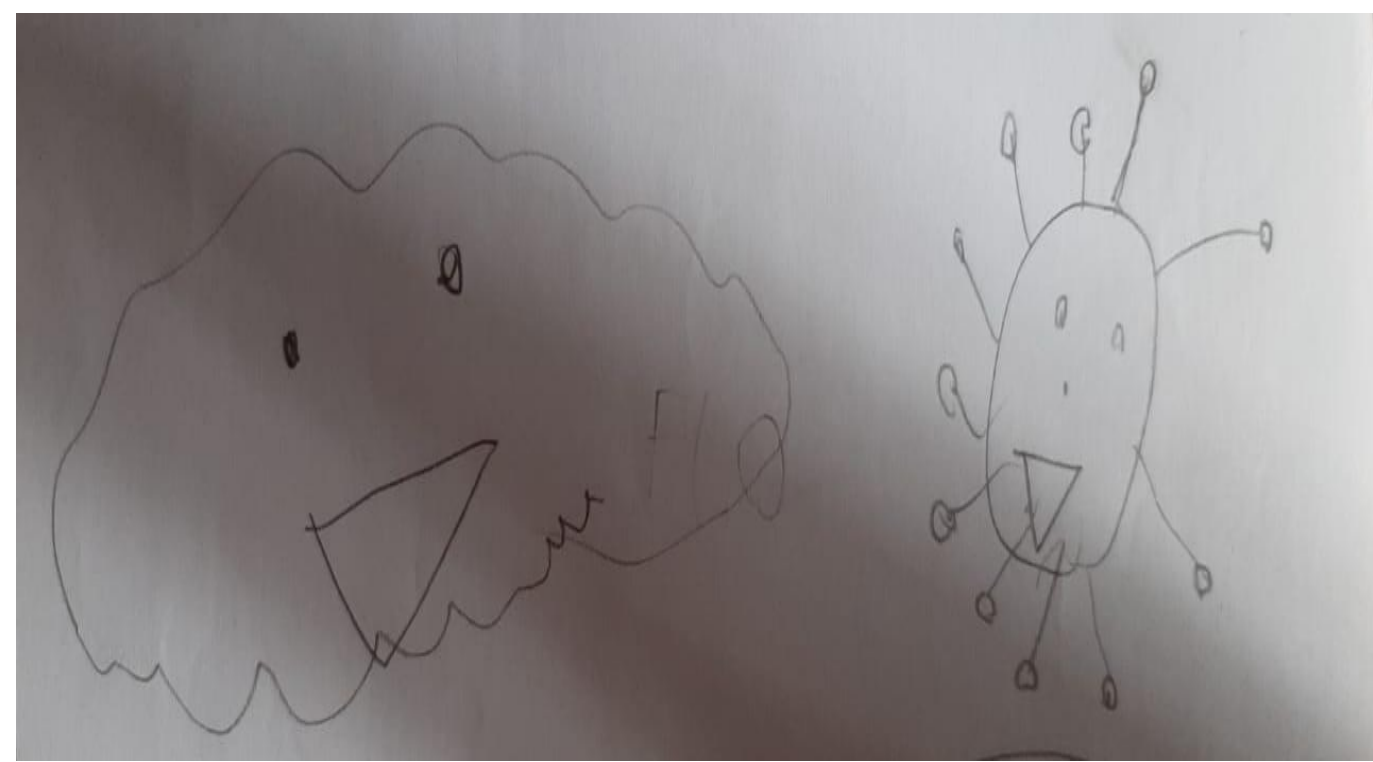

Começo a olhar imagens. Há números por ali.

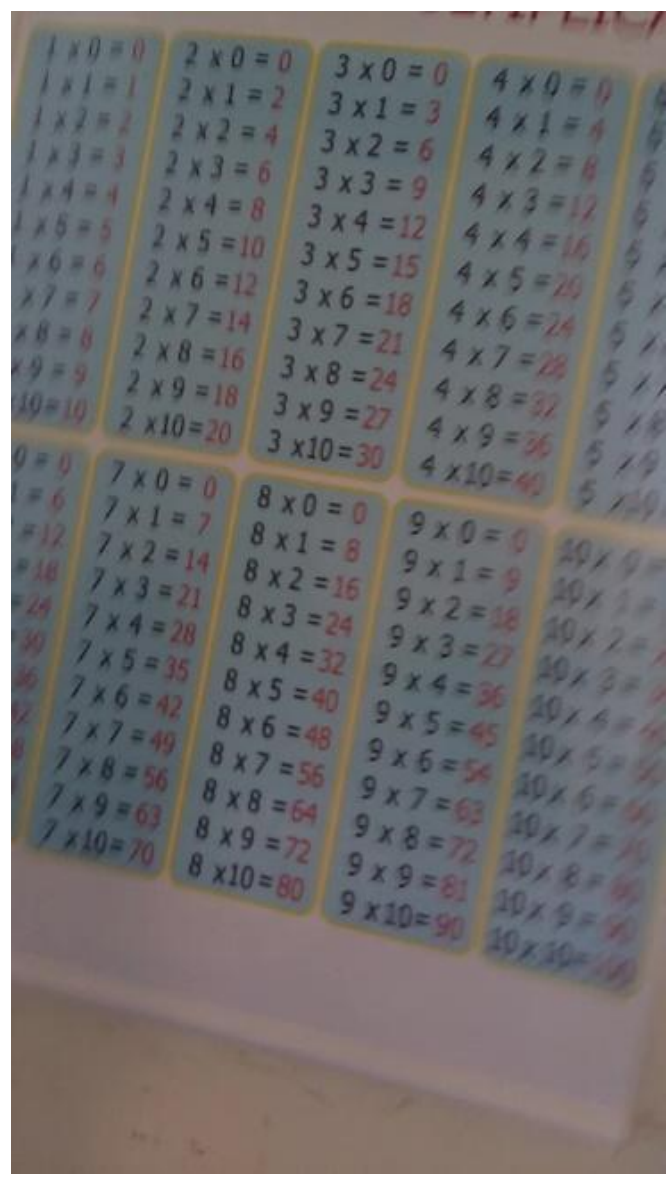

Mas há, inundando tudo, outras coisas. Outras respostas para a pergunta que foi lançada. E para a qual eu achava já saber a resposta. 

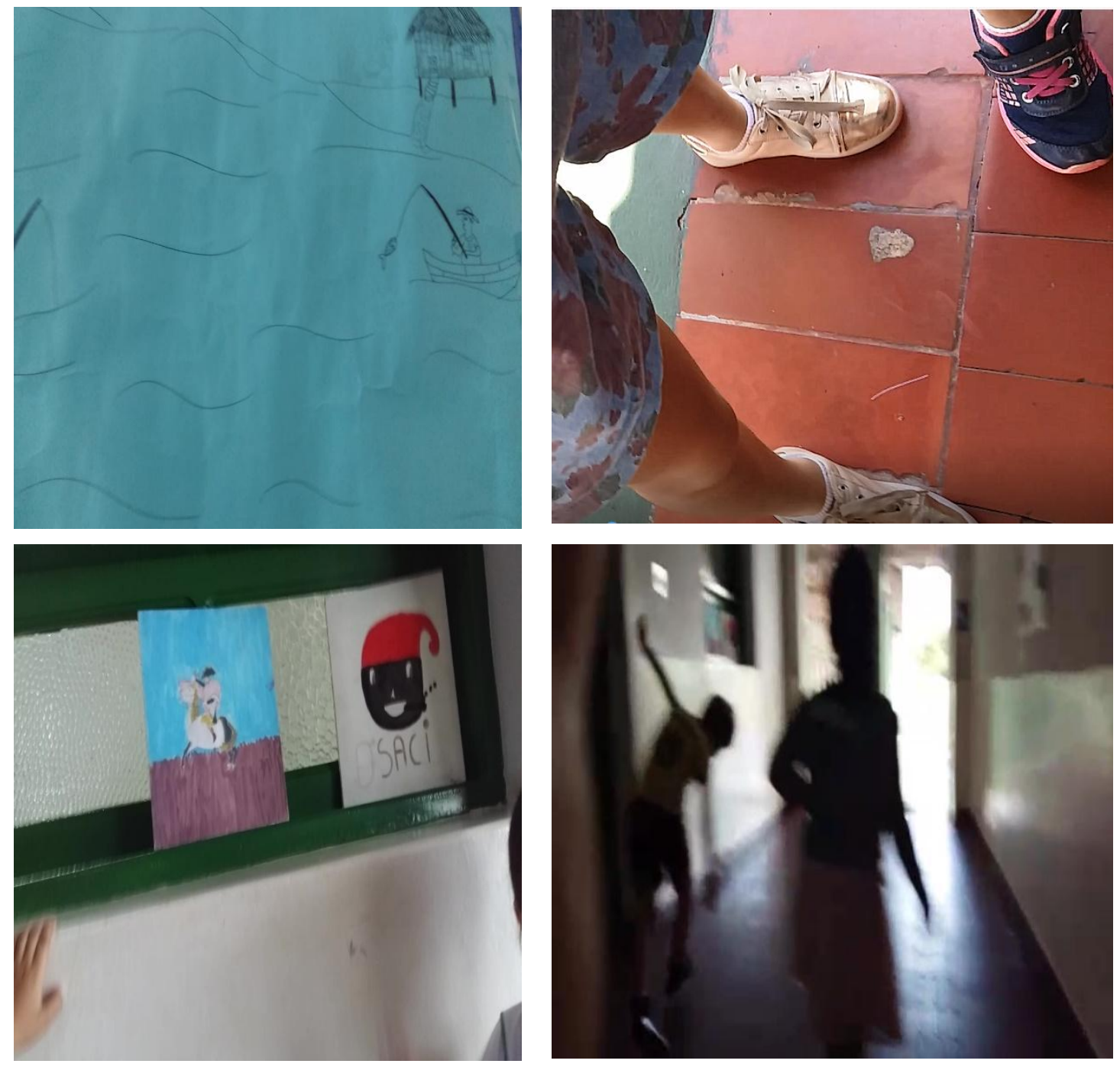

Há dezenas como essas. Todas rompendo com minha formação. Com o esperado. $\mathrm{O}$ que fazer com isso?

Também surgem, em meio às imagens, as falas das crianças sobre matemática e sobre as descobertas dentro de um prédio que elas já viram diversas vezes, mas que ainda apresenta para elas novidade e encantamento.

- Felipe: Ui,ui,ui, caiu o celular

- Mateus: Eu adoro andar de cavalo!

- Maria: Eu adoro andar de cavalo!

- Guilherme: E eu adoro andar de cavalo também!

- Laura: E eu também adoro andar de cavalo, mas cavalo é muito grandão.

- Mateus: E eu adoro laçar também. Ir no clube do laço.

- Laura: E eu adoro ser professora de matemática também. Matemática é continha.

-Mateus: Eu adoro é esse cacto aqui.

- Emanuelly: Ai meu Deus, eu tô com um pouco de vergonha, mas tá legal. Eu vou até dançar.

-Heitor: Ma-ter-nal e os desenhos.

- Duda: Isso aí é matemática?

- Felipe: Eu não sei não. 
-Heitor: É sim, igual os números são matemática. É a mesma coisa.

Fico horas e mais horas olhando e lendo tudo, várias vezes. No fim do dia, fecho os livros de análise, deixo de lado as rotas estabelecidas. Sigo para a ponte.

A ponte está vazia porque já é fim de tarde e os estrangeiros já passaram de volta para o nosso lado, acompanhados por seus responsáveis. Está meio nublado, como sempre. Há poucas pessoas andando nas redondezas e todos me lançam um olhar de estranhamento. A ponte é usada para atravessar, e quem não tem obrigação de passar por ali nem chega perto. Há sempre um discurso sobre a ponte de que quando deixamos de atravessá-la finalmente fazemos parte de nossa sociedade. Há os que trabalham formando para além dela, mas mesmos esses passam ali por um bem maior, o do vilarejo. Quem ainda tem que atravessar a ponte para ter a formação básica é visto como alguém de fora, ainda na marginalidade de uma sociedade que já estabeleceu padrões que devem ser reproduzidos ${ }^{6}$.

Nos dias que se passam eu continuo indo à ponte. Às vezes até o prédio imponente onde os estrangeiros ficam, às vezes não atravessando-a. Apenas deixo que minhas pernas se pendurem, balançando quase como as pernas dos estrangeiros nas carteiras enfileiradas. Paralisados por nossas normas, mas ainda fazendo pequenos movimentos, mostrando que ainda resistem. Meu incômodo aumenta a cada dia e, então, marco com minha orientadora um encontro.

Estou na ponte aguardando. Quando disse o local ela se surpreendeu, mas respondeu rapidamente que viria. Eu trouxe duas imagens para que ela veja. Eu as adoro agora. Nos últimos dias estive lendo algumas coisas, de outros vilarejos. Escritas diferentes das que eu estava acostumada. Poesias, livros de contos, outras teorias de formações possíveis ${ }^{7}$. Descubro outro nome para a estrangeiridade: infância. Quero conversar com a orientadora sobre isso. Sobre outras possibilidades.

Isadora se senta ao meu lado, também com as pernas balançando.

- Que lugar mais diferente. Sinceramente nunca imaginei me sentar aqui para uma reunião de trabalho. Confesso que gostei - ela diz sorrindo.

- Pois é, descobri esses dias, depois de andar por aí angustiada - eu respondo.

\footnotetext{
${ }^{6}$ CHISTÉ; SANTOS (2019)

7 AGAMBEN (2005); SCHERER (2009); CORAZZA; TADEU (2003).
} 
- E imagino que as produções dos estrangeiros tenham causado essa angústia, não é? Olhei o material que você enviou para mim. São realmente preciosidades. E também me deixaram angustiada. Para além de não responderem o que esperávamos, eles apresentaram outras potências para nós, Laura. O que você vai fazer com isso?

- Eu trouxe duas imagens, Isadora. Duas que me fazem sorrir e que me dão muito em que pensar.

Mostro as fotos para a Isadora.
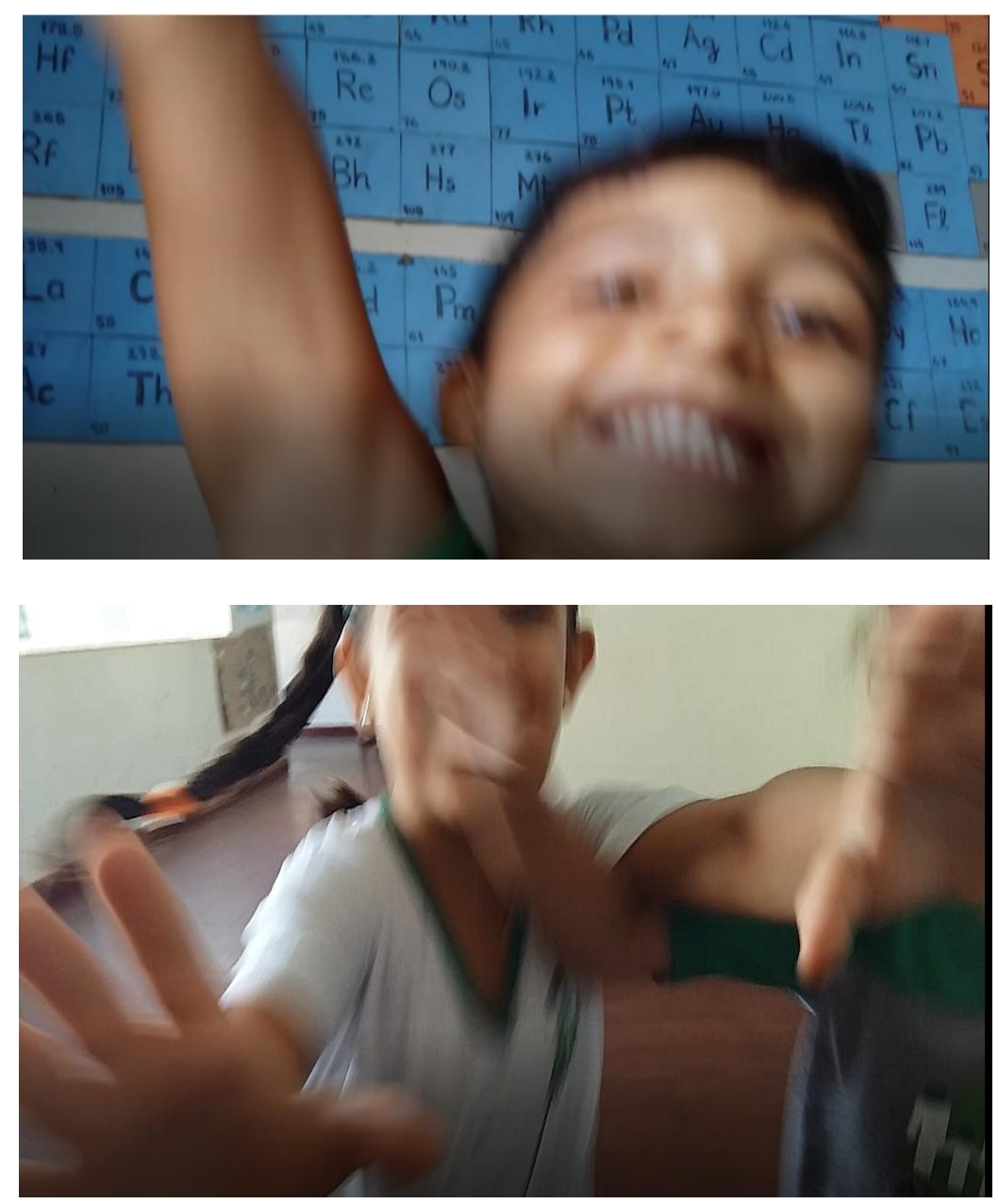

- Na primeira vez quis olhar para essas produções com meu olhar de cima, com minhas formas prontas. Repeti algo que aprendi que é certo, que é válido. Os estrangeiros estão em formação, não é? Então somos nós que damos as respostas, que ensinamos a ser. E então, quando eles produziram isso, quando eles deram outras respostas, quando eles mostraram que pode haver algo além do modelo único de resposta, eu congelei. $\mathrm{E}$ então comecei a ler outras coisas, de outros vilarejos. Poesia, contos, teoria. Eu li um conto que fala que essa fase dos estrangeiros, a infância, é fase de adiamentos. De espera. Que 
Ihe tiramos a fonte dessa vida ${ }^{8}$. Li também Manoel de Barros, já ouviu falar dele? Ele fala sobre a estrangeiridade como potência para romper modos de formar na vida. Desformar. Ele usa esse termo. Os estrangeiros 'desformam' e nós fazemos o quê? Os ensinamos a repetir, repetir, até que a 'desformação' pare e se encaixe em nossa formação. Mas será que se pode repetir e repetir e repetir até ficar diferente? ${ }^{9}$ Será que há a possibilidade de que não haja mais um único modelo, uma única resposta? Será que atravessar a ponte não seja mais sinônimo de ausência, mais de convite para habitarmos outros lugares? Convite para uma novidade, para olhares de encantamento, para que o modo mecânico em que vivemos possa ser rompido? Será que podemos abandonar o único modo de espera ${ }^{10}$

Isadora está me ouvindo, também com os pés balançando. Ela me olha longamente e diz:

- Você sabe que eu tenho um estrangeiro, não é? Sabe que também estou passando por esse processo de formação com ele. Tenho me preocupado muito com o modo como tiramos o encanto dele, o seu movimento de invenção, de criação. Tiramos a diferença, para repetir o padrão, a norma. Eu li O Pequeno Príncipe, recentemente. No primeiro capítulo o menino desenha uma jiboia que engoliu um elefante. Quando ele mostra todos dizem que é um chapéu. Ele então faz a jiboia aberta e o que acontece? Ele é aconselhado a deixar de lado esses desenhos. E então, ele deixou de falar de jibóias abertas ou fechadas ou estrelas. Falava só sobre coisas razoáveis, entendíveis para adultos ${ }^{11}$. Tenho percebido que isso acontece muito em nosso vilarejo, Laura. Acho que talvez possamos começar a pensar sobre isso, a questionar e apresentar outros modos de formar. Poderíamos além do chapéu formar também com a jiboia que engoliu o elefante? As produções das crianças criaram, inventaram outras línguas, outros mundos, outras vidas. Nos desformaram. Mas isso não vai ser fácil, natural, até porque nós já estamos habituados a essa hierarquia, a essa formação, a enxergar apenas o chapéu. É uma escolha sua: manter as naturalidades ou transver o mundo?

Minha avó ouviu tudo calmamente, sem se levantar. Sinal de que ela realmente se interessou. Quando termino ela fica em silêncio por alguns minutos. Vou à cozinha, pego mais bolo e aguardo. E então, ela começa:

\footnotetext{
${ }^{8}$ COUTO (2013).

9 BARROS $(2006 ; 2010 ; 2015)$.

${ }^{10}$ FRANCO (2019).

${ }^{11}$ SAINT-EXUPÉRY (2016).
} 
- Eu já estou no fim da vida e tenho ouvido cada vez mais que me pareço com os estrangeiros de novo. Ouço isso porque não deixei pintarem as paredes da minha casa, porque me recuso a deixar que digam o que e como devo fazer. Parece que estão me formando de novo, para que fique mais fácil para eles. Para que eles possam me controlar melhor. Perceba que nosso vilarejo é organizado de forma a nos governar melhor. Os que estão no começo da vida e precisam aprender a seguir o modelo, e então os produtivos e os que estão na mesma situação que eu, os velhos. No fim da vida. E mesmo assim eles ainda criam modos de me governar para que eu não atrapalhe esse funcionamento. Minha filha, eu adoraria viver em um lugar em que pelo menos um pouco disso fosse deixado de lado. Se você tem a oportunidade de plantar essa sementinha, você deve fazer. Porque não são só os estrangeiros que são controlados, minha filha. Somos todos nós.

Ela então se levanta e volta com um livro. Pede para que eu encontre um poema de Fernando Pessoa e leia. É assim:

O que nós vemos das coisas são as coisas.

Porque veríamos nós uma coisa se houvesse outra?

Porque é que ver e ouvir seria iludirmo-nos?

Se ver e ouvir são ver e ouvir?

O essencial é saber ver,

Saber ver sem estar a pensar,

Saber ver quando se vê,

E nem pensar quando se vê,

Nem ver quando se pensa.

Mas isso (triste de nós que trazemos a alma vestida!),

Isso exige um estudo profundo,

Uma aprendizagem de desaprender

E uma sequestração na liberdade daquele convento

De que os poetas dizem que as estrelas são as freiras eternas

E as flores as penitentes convictas de um só dia,

Mas onde afinal as estrelas não são senão estrelas

Nem as flores senão flores,

Sendo por isso que lhes chamamos estrelas e flores ${ }^{12}$.

Quando termino ela diz:

- A gente acha que sabe tanto, por isso formamos. Talvez, minha querida, tenhamos que aprender a desaprender. Talvez a gente não tenha que saber tanto assim.

O que é matemática? A pergunta ainda me acompanha. Recebi algumas respostas sobre ela que eram esperadas, mas não é delas que quero falar hoje, até porque eu já sei quais são as esperadas, nós já falamos muito delas há muito tempo. Quero falar das outras. É o dia de apresentar meus resultados. Eu deveria fazer isso no prédio de formação, mas

12 PESSOA (2006).

Revista Digital do LAV - Santa Maria - vol. 14, n. 2, p. 281 - 296 - mai./ago. 2021 ISSN 1983 - 7348 http://dx.doi.org/10.5902/1983734865535 
estou na ponte, sentada. Talvez ali, no entre, possamos começar algo novo, mesmo que já pareça que conhecemos tudo ali. Surpreendentemente, é o dia menos nublado que me lembro de ter visto por ali. Os avaliadores estão lá, à espera. Entreguei a eles uma cópia do que vou ler. Me sento na ponte, as pernas balançando, um movimento de resistência em meio à rigidez. Olho para a foto que acompanha as escritas: imponente, avassaladora, intensa, revolucionária. Começo.

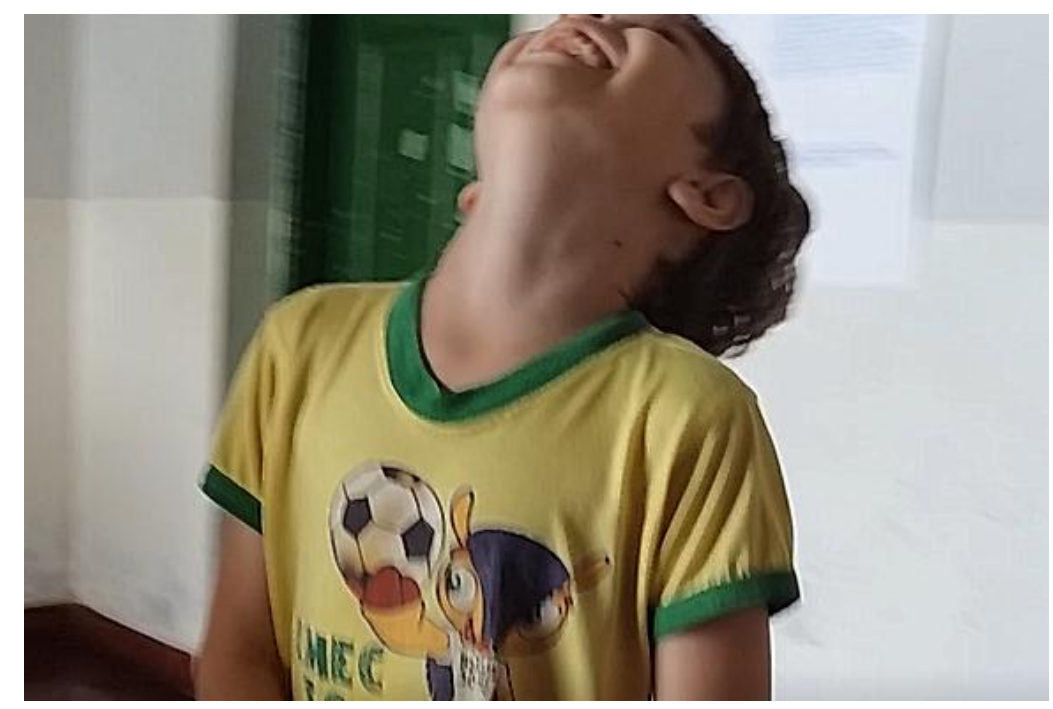

Como é que é ser?

Ser criança? Adulto? Gente?

Como é?

Ensinam. Repetidamente.

Faz assim. Escreve assim. Desenha assim.

Tem que escrever dentro das linhas e desenhar também.

Tem que viver assim, aprender assim, falar assim.

Do jeito que fazemos.

Do jeito que sempre fizemos.

Copie. Reproduza.

Espere.

Sempre um dia nublado.

Sempre tudo pronto.

Mas e se...

não disserem como ser?

E se puder ser pelos sentidos, pelos desejos?

E se fazermos sempre um novo mundo

Não achar nada pronto?

Se não disserem como ser 
Não haverá espera

Não haverá o quando

E sim o agora

Em constante construção de vidas

De mundos

Será sempre um dia de sol.

Termino de ler e levanto os olhos para os formadores que estão me olhando. Depois de ler as palavras que me escaparam, o sol já está mais forte e consigo enxergar até a sombra de meu corpo, estendendo-se pela ponte. Iluminada pelos raios fracos, mas que já são suficientes para romper a camada de nuvens, pergunto: por quanto tempo vamos esperar para ser verão?

\section{Referências}

AGAMBEN, G. Infância e História: destruição da experiência e origem da história. Tradução de Henrique Burigo. Belo Horizonte: Editora UFMG, 2005.

BARROS. M. de. Memórias Inventadas a segunda infância. São Paulo: Planeta, 2006.

BARROS, M. Poesia Completa. São Paulo: Leya, 2010.

BARROS, M. Meu quintal é maior do que o mundo. Rio de Janeiro: Objetiva, 2015.

BRITO, M. dos R. de. Da formação à deformação: para além da fundamentação. IXTLI: Revista Latinoamericana de Filosofía de la Educación, v. 3, n. 5, p. 85-104, 2016.

CHISTÉ, B. S. Devir - criança da matemática: experiências educativas infantis imagéticas. 2015. 106f. Tese de Doutorado (Doutorado em Educação Matemática) Universidade Estadual Paulista Júlio de Mesquita Filho, Rio Claro - SP, 2015.

CHISTÉ, B. S.; SANTOS, G. T. dos. Se Essa Rua Fosse Minha... Entre Imagens e Infâncias: mapas, rastros e traços do corpo-criança. Rev. Bras. Estud. Presença, Porto Alegre, v. 9, n. 4, p. 1-23, 2019.

CHISTÉ, B. S.; MIZUSAKI, R. A.; ANDRADE, F. S. de. Corpos resistentes e infâncias insubordinadas: produzindo outros sentidos na/para escola - Grupo de estudos pedagógicos. In: Anais... II Seminário sobre infância e Pós-Colonialismo: pesquisa em busca de pedagogias descolonizadoras. Campinas/SP: 2015.

COUTO, M. A menina sem palavra. São Paulo: Boa Companhia, 2013.

CORAZZA, S. TADEU, T. Composições. Belo Horizonte: Autêntica, 2003.

FRANCO, V. N. M. Entre infâncias, narrativas e delírios: fora da escola, fora da matemática, fora do risco. 2019. 188f. Dissertação (Programa de Pós-Graduação em Educação Matemática) - Universidade Federal de Mato Grosso do Sul, Campo Grande/MS, 2019. 
KOHAN, W. Infância. Entre Educação e Filosofia. Belo Horizonte: Autêntica, 2005.

KOHAN, W. O. Apontamentos filosóficos para uma (nova) política e uma (também nova) educação da in-fância. In: Anais... Reunião Anual da ANPED. Caxambu/MG: 2004.

MEDEIROS, A. S. de. Devires de Imagens: atitudes e matemática(s) construídas e praticadas por um grupo de crianças. 2018. 124f. Dissertação (Programa de PósGraduação em Educação Matemática) - Universidade Federal de Mato Grosso do Sul, Campo Grande/MS, 2018.

PESSOA, F. Poemas Completos de Alberto Caeiro. Editorial Verdehalago, 2006.

RIBETTO, A. Experiência, experimentações e restos na escrita acadêmica. In: CALLAI, C.; RIBETTO, A. (org.). Uma escrita acadêmica outra: ensaios, experiências e invenções. 1. ed. Rio de Janeiro: Lamparina/FAPERJ, v. 1, p. 58-67, 2016.

RILKE, R. M. Cartas do poeta sobre a vida. São Paulo: Martins Fontes, 2007.

ROLNIK, S. Cartografia sentimental: transformações contemporâneas do desejo. 2. ed. Porto Alegre: Sulina, Editora da UFRGS, 2016.

SAINT-EXUPÉRY, A. O Pequeno Príncipe. Tradução de Bruno Anselmi Matangrano. São Paulo: Pé de Letra, 2016.

SCHÉRER, R. Infantis: Charles Fourier e a infância para além das crianças. Belo Horizonte: Autêntica Editora, 2009.

\footnotetext{
' Doutoranda do Programa de Pós-Graduação em Educação Matemática da Universidade Federal de Mato Grosso do Sul. Possui graduação em matemática pela Universidade Federal de Mato Grosso do Sul (2016) e é mestra em Educação Matemática também pela Universidade Federal de Mato Grosso do Sul (2018). Membro do Grupo GETECMAT.

ii Doutora em Educação Matemática pela UNESP/Rio Claro. Docente do Instituto de Matemática da UFMS. Possui Bacharelado em Matemática pela Universidade de São Paulo (2007) e Licenciatura em Matemática pela Universidade de São Paulo (2008). Mestrado em Educação Matemática pela Universidade Federal de Mato Grosso do Sul (2011) e Doutorado em Educação Matemática pela Universidade Estadual Paulista "Júlio de Mesquita Filho" (2015). Atualmente é Docente Adjunta A2 do Instituto de Matemática da Universidade Federal de Mato Grosso do Sul, credenciada ao Programa de Pós-graduação em Educação Matemática da mesma instituição.
}

Como citar esse artigo:

MEDEIROS, Amanda Silva; CHIARI, Aparecida Santana de Souza. Infância e Educação Matemática: um conto sobre quando, enfim, somos verão. Revista Digital do LAV, Santa Maria: UFSM, v. 14, n. 2, p. 281-296, mai./ago. 2021. 